\title{
Setting Things Before the Mind
}

$\mathrm{L}$

istening to someone from some distance in a crowded room you may experience the following phenomenon: when looking at them speak, you may both hear and see where the source of the sounds is; but when your eyes are turned elsewhere, you may no longer be able to detect exactly where the voice must be coming from. With your eyes again fixed on the speaker, and the movement of her lips a clear sense of the source of the sound will return. This 'ventriloquist' effect reflects the ways in which visual cognition can dominate auditory perception. And this phenomenological observation is one that you can verify or disconfirm in your own case just by the slightest reflection on what it is like for you to listen to someone with or without visual contact with them.

A common assumption in most philosophical discussions of appearances and experience is that, when one does engage in just such reflection, the character of how things appear to one is just obvious to one. Just this assumption seems to lie behind Ned Block's comment

...what is it that philosophers have called qualitative states?: As Louis Armstrong said when asked what jazz is, "If you got to ask, you ain't never going to get to know."

It is implicit in much of the recent debate about the problems of explaining consciousness, in particular what has come to be called phenomenal consciousness, in purely naturalistic terms: although we may not be able to explain how such consciousness can arise within a physical world, we have a clear sense of what the problematic subject matter is just by focusing on one's own case.

Now while the assumption is widespread, and in many ways seems sensible, it does raise a deep puzzle concerning the ways in which philosophers debate the nature of perception and perceptual appearances. For it is clear in such debate that philosophers disagree, and that they disagree about the nature of appearances. Some philosophers claim that it is just obvious that there aspects of your experience, say of your currently looking at this page, which are entirely independent of any aspect that you may perceive the mind-independent world to 


\section{Setting Things Before the Mind}

have. Others, however, are insistent that it is just obvious to us that our perceptual experiences of the world are purely representational or intentional, and that what it is like to be in such states is a matter of no more than how things are represented as being by those states. It is difficult to interpret these disagreements as other than being disagreements about the nature of appearances, how things look, or feel, or taste to us when we explore the world around us. Yet, if the nature of appearances really is just open to simple reflection, how can there be room for any serious disagreement? Surely one can confirm or disconfirm any theory of appearances straight off. The persistence of disagreement would suggest that either the inner lives of philosophers are much more varied than we previously had reason to suspect, or that at least one party to the debate must be deeply confused.

Instead, I suggest that the fact that such disagreement does occur indicates that there is such conflict implies that even if the character of experience is obvious to us, it is not obvious how obvious it is. To make sense of these different theories, we must interpret them as able to draw a contrast between the real nature of appearances and how their opponents may be misled in describing how such appearances seem. And this thought raises the question whether we can find an appropriate common ground among parties to the dispute: some description of what experience is like which neutrally expresses how appearances seem to us. We could then see the competing parties as attempting to give competing explanations of this common ground.

It is this interpretative task that I attempt to undertake in this paper. I shall not offering any final or definitive account of the nature of perceptual experience or the relation between experience and perception in this talk. On the other hand, the reader is sure to be able to find many such accounts in other discussions of perception. It is more difficult, however, to discern the common root or the starting point for these incompatible accounts of the supposedly obvious, and that is why I trust there is sufficient interest in trying to find a suitable overview of the disagreements here. 


\section{Setting Things Before the Mind}

1. In recent discussion, the notion of qualia has dominated debate about the nature of sensory consciousness. This has occurred particularly in the context of debate about the viability of a purely physicalist understanding of the mind. A common view is that the intentional or representational properties of mind, those in virtue of which our thoughts are about objects or properties in the world around us, present no insuperable problem to a physicalist account of the mind. In contrast, it has been suggested that the fact that we are conscious, and more specifically that we have sensory or phenomenal consciousness, has been thought inexplicable given the state of neurosciences and cognitive psychology. Associated with posing the problem in this way is the thought that if we do have phenomenal consciousness, then such consciousness is not to be understood in representational terms.

I want first to focus critically on the notion of qualia since it stands in the way of our getting a proper over-view of the disagreements concerning the nature of perceptual experience. Although many philosophers write as if it is simply obvious to us that there are qualia, and that we know what they are, I shall argue instead that this is all chimerical. For the most common usage of the term 'qualia' is equivocal, and the most familiar means of elucidating the term, by a kind of inner ostension of one's conscious states simply fails to pick out a unique target. Furthermore, lying behind this confusion is a long-standing dispute about the nature of experience and our knowledge of it which needs to be made explicit before we can advance in our task of setting up a common framework for understanding the debate about perception.

The term has been used in a number of different ways, but we would do well to start with the usage found in this passage from David Chalmers:

...a mental state is conscious if there is something it is like to be in that mental state. To put it another way, we can say that a mental state is conscious if it has a qualitative feel-an associated quality of experience. These phenomenal feels are also known as phenomenal qualities, or qualia for short. ${ }^{1}$

\footnotetext{
${ }^{1}$ D. Chalmers, The Conscious Mind(Oxford: Oxford University Press, 1996), p.4.
} 


\section{Setting Things Before the Mind}

So used, the term is intended to pick out in the most general and neutral way the various aspects of conscious episodes. In taking conscious experience to be suitably evident to a reflective audience, philosophers often avoid any explicit or informative definition of the term 'qualia'. Indeed, it is sometimes suggested that no informative definition could be given. Instead, we are often offered a verbal equivalent of an inwardly directed gesture, which in the context of the discussion is intended to direct one's attention on the appropriate subject matter. While it is generally assumed that it is simply obvious to us then what qualia are to be taken to be, I shall argue that in fact the term is generally used equivocally, and that independent of some further clarification, we cannot determine how people are using the term.

We can trace the equivocation to the way in which we are introduced to the term. A notable such example is provided by Daniel Dennett, in a discussion which more generally is hostile to the notion of qualia. Despite Dennett's hostility to the notion, his opponents have been happy to accept his initial elucidation of the notion right at the outset of his paper. It is worth looking at in some detail:

'Qualia' is an unfamiliar term for something that could not be more familiar to each of us: the ways things seem to us... Look at a glass of milk at sunset; the way it looks to you - the particular, personal, subjective visual quality of the glass of milk is the quale of your visual experience at the moment. The way the milk tastes to you then is another, gustatory quale, and how it sounds to you as you swallow is an auditory quale. These various 'properties of conscious experience' are prime examples of qualia. ${ }^{2}$

Now this gloss on what Dennett complains is 'frustratingly elusive' contains a central, and, I shall argue, significant problem: Dennett equivocates on the term 'qualia' even as he introduces it. As the last sentence of the passage makes clear, and as the course of the paper it comes from also indicates, Dennett assumes, with many other authors, that we should use the term 'qualia' to pick out 'properties of experience'. We may think of seeing a glass, or more neutrally having a visual

\footnotetext{
${ }^{2}$ D. Dennett, 'Quining Qualia', Consciousness and Contemporary Science, A. Marcel and E. Bisiach (eds.) (Oxford: Clarendon Press, 1988), p.42.
} 


\section{Setting Things Before the Mind}

experience as of a glass, as being a state of mind, the having of an experience. Someone who has such an experience thereby has the property of having an experience of a glass. Qualia are then to be seen either as properties of properties - that is what it is like to have an experience of a glass is a property of having the property of having an experience of the glass. Alternatively, we can think of the ways in which things seem to one as further determinations or specifications of the determinable, having an experience. Each of the specific experiences that you might have: the feeling of the hardness of the chair beneath you, hearing the rustle of frustration around you, each are different ways of having an experience. Qualia are then just these different ways of having experience. However, Dennett does not stick with this usage, for the moment he gives us any concrete examples of qualia we seem to shift to something of an entirely different order to that of a property of an experience: for Dennett's examples are themselves not properties of experiences, but properties of the objects we come to perceive. He writes first of the way the glass of milk looks to one, where the object which has the property is itself part of the world around us and not part of the mind, namely a glass. Likewise, it is the particular quantity of milk which tastes some way to one, and the milk, one's throat, (and lack of manners) all together which are responsible for the sound which Dennett picks out as a auditory quale. But surely nothing can both be the property of an object independent of the mind and at the same time a way of having an experience. So Dennett seems to have introduced just the wrong examples to indicate as 'properties of experience'.

It is not difficult to see where the problematic ambiguity is introduced in the discussion. For the phrase 'the ways things seem to us' is itself ambiguous. Dennett, and others, seek to introduce the term 'qualia' by reference to such English locutions for how things look, feel, sound or more generally appear. But appearance talk is itself complex and hence allows for abstraction of terms in more than one way. The different instructions for fixing on an example of a quale result from abstracting now in one way, and now in another.

For example, when I tell you:

It looks to Dan as if there is a rosy-hued glass of milk before him 


\section{Setting Things Before the Mind}

I may intend to emphasise how things are with Dan, and to contrast the fact that Dan has a certain kind of experience with the fact that Mary is asleep, or that Ben has an altogether different kind of experience. So we can imagine that the following underlined aspect of the sentence would be up for substitution in contrasting the way Dan is, with how else he might have been:

(1') It looks to Dan as if there is a rosy-hued glass of milk before him

On the other hand, given that this is in fact a case in which Dan is perceiving the glass of milk, we might rather be interested in what aspects of the milk are evident to Dan. In this case we may be interested that it is the specific shade that the milk has that is manifest to him, in contrast to the maker's mark on the glass. In that case, the following underlined aspect of the sentence would be open to substitution to contrast ways in which the situation might have differed:

(1") It looks to Dan as if there is a rosy-hued glass of milk before him

So in moving from talk of something appearing $F$ to someone, to talk of appearances, qualities of experience or qualia, the loss in complexity of the semantic structure leaves one open to equivocation between properties of what appears and properties of what is appeared to. Just such slippage occurs in the passage quoted from Dennett: within one paragraph we move from properties of experience to properties of the object of experience, the glass of milk, back to properties of experience again.

Dennett is not an isolated example of this shift, but perhaps we can make do with just one other more recent example. Fred Dretske, like Dennett, is hostile to a tradition of thought which sees qualia as presenting an insuperable problem for a naturalistic account of the mind. In his monograph

Naturalizing the Mind, Dretske puts forward 'the Representational Thesis' as his account of how the mind can be part of the natural order. The thesis itself consists of two claims: '(1) All mental facts are representational facts, and (2) All 


\section{Setting Things Before the Mind}

representational facts are facts about informational functions. ${ }^{3}$ When Dretske turns to the issues raised by conscious experience in the third lecture, he makes the following claim:

The Representational Thesis identifies the qualities of experience-qualia - with the properties objects are represented ${ }_{s}$ as having. ${ }^{4}$

Whatever one thinks of the Representational Thesis itself, one ought to hesitate before accepting this identity claim as a consequence of it. As the first half of the identity claim makes clear, qualia are assumed to be properties of experiences, properties of properties of one's mind, or ways in which one may come to have an experience. But Dretske, as with most philosophers who ascribe a representational content to experience, supposes that our experiences represent how objects independent of the mind are. Such mind-independent objects cannot have properties which are properties of states of mind. So it is implausible to suppose that our experiences should represent mind-independent objects as having properties of states of mind. Yet this manifest absurdity is what Dretske claims in this passage.

Well, if we try to reconstruct what Dretske might be trying to say here, we can see the same equivocation in play as in the Dennett. Although Dretske starts the sentence by talking about qualities of experience, the only intelligible claim he could be making is one which identifies qualia understood as the properties objects appear to have with the properties our experiences represent those objects as having. This thesis is perfectly intelligible, even if some people might find it mildly controversial.

On the other hand, one might think that this identity claim alone falls short of telling us much about what experiences are like, and how Dretske's position differs from those who insist that there are qualia but who reject the

\footnotetext{
${ }^{3}$ F. Dretske, Naturalizing the Mind(Cambridge, MA: MIT Press, 1995), p.xiii.

${ }^{4}$ Op. Cit. p.65: 'represents' is Dretske's term for sensory or phenomenal representation as opposed to conceptual representationthe details of the distinction he draws has no import for the point made in the text.
} 


\section{Setting Things Before the Mind}

Representational Thesis. But the need for Dretske to link up claims about how objects may come to appear to have properties with claims about what our experience can be like is obscured for him by the use of the equivocal term 'qualia'. Since he can now use it in one sense, now in another, it may seem as if he covers all angles at once.

This example not only increases our sample of equivocal uses, but directs us towards the significance of this slip of the pen. For it would be mistaken to respond to this problem by claiming that we can easily re-interpret both authors so as to avoid any such equivocation and ambiguity. A charitable response to these problems would no doubt be one which understood both authors as intending strictly just to talk about the properties of what experiences are like when they talk of qualia, and hence to re-interpret any passages where they slip into talking instead of the properties that objects appear to have. But one could undertake this interpretative task only if we could reconstruct the theses put forward solely in terms of properties of experience on the one hand, and properties that objects appear to have on the other. Once we make the distinction we can see that the theories do not offer us any explicit account of how the two sets of properties are related, even though the equivocation between the two suggests that in interpreting the notion of qualia we are to understand that there should be some important relation between them.

Indeed, the need to do so can be made even more explicit by setting this issue in an historical context with which it is not normally associated, that between sense-datum theories of perception and so-called adverbial approaches. Consider first this notorious passage from $\mathrm{HH}$ Price:

When I see a tomato there is much that I can doubt. I can doubt whether it is a tomato that I am seeing, and not a cleverly painted piece of wax. I can doubt whether there is a material thing there at all... One thing however I cannot doubt: that there exists a red patch of a round and somewhat bulgy shape, standing out from a background of other colour-patches, and having a certain visual depth, and that this whole field of colour is presented to my consciousness...that something is red and round then and there I cannot doubt...that it now exists, and that $I$ am conscious of itby me at least who am conscious of it this cannot possibly be doubted... This peculiar and ultimate manner of being present 


\section{Setting Things Before the Mind}

to consciousness is called being given, and that which is thus present is called a datum. ${ }^{5}$

Perhaps the most salient aspect of this picture of perception and experience are those aspects of it which used to be called 'the act-object' model of experience. According to Price the occurrence of an experience involves a subject, a relation of being given which relates that subject to various objects, the data, which are presented or given to her. Furthermore, Price is insistent that such objects will be present even in cases of illusion or hallucination, so at least some of these data are nonphysical.

However, the passage is of most concern to us for the kind of view of knowledge of experience that it expresses. For Price seems to be of the view that one knows about the character of one's experience, that some red bulgy thing is present to one's mind, through attending to the object which is given in the experience, the red bulgy thing itself. Indeed, like Moore before him, Price thinks that consciousness is entirely diaphanous, and hence that all differences between conscious states of mind are differences in the objects which those states can have. ${ }^{6}$ So, when one comes to know what one's experience is like, and how it may differ from other conscious states one could have come to have, one does so through attending to the objects of awareness given to one through having such states.

In the middle of the twentieth century, sense-datum theories, as 'act-object' accounts of experience, provoked an alternative kind of account normally known as 'adverbial' theories of perception. The epithet comes from a suggestion first made by CJ Ducasse, in response to Moore that:

"blue," "bitter," "sweet," etc., are names not of objects of experience nor of species of objects of experience but of species of experience itself. What this means is perhaps made clearest by saying that to sense blue is then to sense bluely, just as to dance the waltz is to dance "waltzily" (i.e., in the manner called "to

\footnotetext{
${ }^{5}$ H. H. Price, Perception(London: Methuen, 1932), p.3.

${ }^{6}$ Moore's opinion can be found in G. Moore, 'The Refutation of Idealism', Philosophical Studies, (London: Routledge \& Kegan Paul, 1922); Price commits himself to the view op. cit. p. 5.
} 


\section{Setting Things Before the Mind}

waltz") to jump a leap is to jump "leapily" (i.e., in the manner called to leap) etc. ${ }^{7}$

The primary motivation for such adverbialism is to avoid any commitment to the existence of non-physical objects of the sort that Price is happy to accept. The assumption of such discussions is that a commitment to ways in which one experiences, as opposed to objects which one senses, cannot be thought objectionable since we will be committed to the existence of such states of mind, as long we are not eliminativist about the mind or sensory consciousness.

But the adverbialism which Ducasse favours goes beyond the purely negative thesis that we should not commit ourselves to the existence of non-physical objects of sense, to a contrasting picture both of the role that experience plays in our perception of the world, and how it can be that we come to be aware of our own experiences. The key idea is that we should principally think of our experiences as effects upon us by the environment; which effects have a distinctive qualitative character, and which are such that they bring about beliefs about the environment. Such states have sufficient dimensions of variation that there can be a reliable connection between environmental conditions which bring them about. In turn such states will act as the causes of beliefs about the presence of such environmental conditions which reliably correlate with the states of affairs they are about. We can think of our descriptions of experience as being of red, or of green triangles, or of musk, all as indicating the kind of cause which brings them about and correlatively the belief which they could reliably fix. On this view, awareness of the objects of perception and how they appear to be is one thing - the mind is directed out at the world - and attention to one's own experience another thing. The experience is a merely a causal intermediary between world and our knowledge of it, our awareness of experience requires directing attention not at the objects of sense, but rather within the mind. ${ }^{8}$

${ }^{7}$ C. Ducasse, 'Moore's "Refutation of Idealism"', The Philosophy of GE Moore, P. A. Schilpp (ed.) (La Salle, Illinois: Open Court, 1942), pp.232-3.

${ }^{8}$ Ducasse's main concern, it must be said is with Moore's contention that the object of consciousness in sensing is independent of the 


\section{Setting Things Before the Mind}

Now if we bracket for the moment a concern with the metaphysical status of the objects of sense, whether they can be non-physical or not, the contrasting attitudes towards knowledge of experience on Price's view and on the adverbialism opposed to it offer us contrasting interpretations of the connection between the properties of what experiences are like, which we can come to be aware of, and the properties which objects appear to us to have. For Price, there is nothing more to learn about the nature of one's experience than to learn what objects, and what qualities of objects are given to one. To learn about the properties of one's experience just is to learn what properties objects are presented as having. We might put this in terms of qualia by saying that on this view, qualia in the sense of the what-it-is-like properties of experience, qualia ${ }_{1}$ as one might say, are partly constituted by the properties which objects appear or are presented as having, qualia ${ }_{2}$. And one comes to know what the qualia ${ }_{1}$ of one's experience are, through knowing what the qualia ${ }_{2}$ of one's experience are. In contrast, for the adverbialist, properties of one's experience need to be sharply distinguished from properties that objects appear to have: the properties objects appear to have, on the whole, are those which our experiences are liable to cause us to believe that they have. The properties our experiences have, qualia ${ }_{1}$, are the properties which are responsible for our coming to acquire these beliefs, but they are distinct and our awareness of them is

mind - and the dispute between Moore and Ducasse involves much talking past each other. For a further development of adverbialism which takes on the elements described in the text, see R. Chisholm, Theory of Knowledge(Englewood Cliffs, NJ: Prentice Hall, 1966), pp.91-98 and M. Tye, 'The Adverbial Approach to Visual

Experience', Philosophical Review XCIII, No. April(1984),195-225. This approach has its roots in Thomas Reid, see T. Reid, 'Essays on the Intellectual Powers of Man', Inquiry and Essays, R. Beanblossom and K. Lehrer (eds.) (Indianapolis: Hackett Publishing Co, 1983). Note that not all philosophers whose views on sensation have been classified as adverbialist have made the assumption about our knowledge of experience mentioned in the text, the most notable exception is Wilfrid Sellars, see 'Empiricism and the Philosophy of Mind', Science, Perception and Reality, (London: Routledge \& Kegan Paul, 1963), and Science and Metaphysics (London: Routledge \& Kegan Paul, 1968). 


\section{Setting Things Before the Mind}

distinct from our awareness of the properties that objects appear to have, qualia ${ }_{2}$.

If we look back to Dretske and Dennett, then we can see this controversy mirrored in what they have to say. In Dretske's case it is clear that the conception of knowledge of experience is closest to the sense-datum approach, although he is surely keen to avoid the metaphysical extravagances of that view: why the identity of qualia ${ }_{2}$ for him with the properties objects are represented as having may be relevant to the Representational Thesis is simply that if one accepts with Price that qualia determine qualia $_{1}$, and that we have knowledge of qualia ${ }_{1}$ through knowledge of qualia ${ }_{2}$, he can claim that our knowledge of what experience is like is simply knowledge of how it represents things to be, and hence knowledge of its representational properties.

With Dennett, on the other hand, it is clear what we could interpret the passage in either way. For if one sides with the adverbialist then, given the close correlations between properties objects can be perceived to have and the experiences to which those objects give rise, one might imagine that thought of the one would be liable to bring to mind the other. Dennett can be seen as employing a form of metonymy, in mentioning the properties the glass of milk may be perceived to have, he enables his audience to latch on instead to the distinct set of properties which one's experiences would have, were one perceiving the milk. Furthermore, since there is no obvious vocabulary for the qualities of experience so conceived, one might think that this is the most natural and obvious way to introduce such ineffable aspects of the mind into conversation.

It is clear that there is a substantive disagreement here over the nature of qualia, even when we restrict that term simply to mean the what-it-is-like properties of experience. The instructions provided for simply directing one's attention to these elusive properties are inadequate to the task of settling which account is the right one; yet the terms in which philosophers discuss these matters tend to equivocate, now between talk of properties of experience, now properties of objects; and the ways in which they talk slip between supporting one account of the relation of these properties, and now 


\section{Setting Things Before the Mind}

supporting the other. ${ }^{9}$ I suggest it is no accident that these two things come together. As long we simply equivocate over the use of the term 'qualia' we can hide from ourselves the need for answering the difficult question how the properties of experience relate to the properties which things appear to have.

2. The issue here is substantive, but how are we to settle it? Well, the idea that our conception of what our experience is like and our conception of what properties objects appear to us to have might be separate is attractive only as long as we look at the simplest of descriptions of experience: for example a visual experience of a red bulgy thing; an experience of a bitter or tangy thing. There seems to be nothing about these descriptions that should make us prefer one account over another. But when we look to more complex cases, we see that the description of what is apparent to us is not independent of our appreciation of what experience is like, and that for some aspects of experience it is difficult to conceive of what they could be independent of how things appear to us. Proper attention to experience, I suggest, shows that the adverbialist conception of our knowledge of experience is in the end unintelligible.

\footnotetext{
${ }^{9}$ Paul Boghossian suggested to me that one could define a perfectly good notion of qualia without this threat of equivocation: qualia just are the non-representational properties of the mind which make a difference to what it is like to be one. We can determine whether there are any qualia, simply by asking whether two individuals could differ with respect to what it is like to be them without differing in their representational properties. However, the problem with this suggestion concerns how we are to apply the test: for in order to use the test within a thought experiment we need to determine when two individuals are to be considered as sharing all the same representational properties. This we cannot do without attending to the properties which things appear to them to have. This, somewhat indirect, test for the existence of qualia implicitly exploits the kind of direct test discussed in the text: we are either meant to recognise those aspects of consciousness which are purely representational or those which are not. So the problem of what one is to direct a subject's attention to, when their attention is directed to the qualitative aspects of sensory experience remains.
} 


\section{Setting Things Before the Mind}

To focus on a concrete example, consider the following passage from a discussion of the nature of shadows by the art theorist Michael Baxandall:

I am writing this at a table with a wall each side of it, on a day of mixed sun and cloud. The wall on the right is modern, made of brick, and painted white with a matte but even emulsion paint. At the base of the wall the paint is blistering from damp. The wall on the left is much older, rough-cast rendering over undressed sandstone masonry, and there have been various attempts to patch gaps in the rendering with cement of various consistencies. It too is painted white, but with a rougher sandtextured stuff. This is flaking off in places due to an impermeable white flint element in the rough-cast; and in some but not all of these places desultory touching up has been done with a different, slick and clinging white paint, some of it applied by a roller and some boldly by a brush. The conspectus of the walls to left and right is almost as monochrome white, nevertheless...

As the sun comes and goes the various kinds of radiation change level by a large factor, certainly to the point of discomfort - there are windows on three sides - and yet the walls remain white: brightness constancy, of course. But, partly because of these shifts between direct strong light and diffused weak light on the monochrome walls, partly because of a special interest, I am very aware of being in an indescribably intricate ambience of microshadow. It may usually be called texture, a word that somehow invokes the sense of touch, but it consists visually of almost pure shadow-very small self-shadows, derived shadows, and slant/tilt shadings... It is almost purely from shadow that my visual access to the microstructure of the two plane surfaces of the walls derives. I do not think stereopsy is helping much.

What I do not do, or would not be doing but for a special interest, is to attend to the individual microshadows as shadows or as objects of perception in their own right. If I attend to part of a wall I get a sense of its surface quality and that seems enough. Even with a special interest, it takes an effort of will, a decree of the mind, to attend to the same area of wall, to categorize its shadow types, and read the bearing of their lighting. 


\section{Setting Things Before the Mind}

It is not an optical problem of acuity, in this strong light; rather, it seems to go against the grain of the perceptual process... ${ }^{10}$

Baxandall is concerned with the question whether 'we can [attend to individual shadows] and at the same time preserve the pattern of our more usual utilisation of the same shadow in the course of normal variously directed perception'. ${ }^{11}$ His concern is with the ways in which we can attend to shadows, the difficulty in doing so, and the ways in which our perception of our environment may subtly change as we do so. In the description of his study, we are given familiar types of description of his surroundings, intermingled with observations about the existence and nature of certain types of shadow and visual phenomena, together with some technical commentary on the physical nature of the light array. These three elements mingled together may give one a greater or lesser sense of what it must have been like for Baxandall glancing over his study and staring out at the countryside beyond. The more one knows the kind of room discussed, the more one can link it with one's own knowledge of what it must have been like; the more one follows Baxandall in attempting to attend to elements of the visual array, and discern the structure of shadows, the more one has the sense of what he has done, and how one can do it well or badly. However, the passage is also a bravura display of how one might try to describe a visual scene combining such elements: Baxandall draws our attention at least as much to what he is reporting himself as doing and how he is reporting it, as to what he discerns; we have the sense of what it is like keenly to attend to the visual world, so as to discern various of its elements, and the difficulty and effort involved in drawing out the role of shadow in our visual perception of the world.

One might react to this passage by wondering what its bearing is on the question we are interested in, namely the nature of experience and our first person access to it. One might think that while it tells us much, more than we wished to know, about what its author perceived that afternoon in the environment around him, it does not tell us about his experience. But such a response, I suggest, would be wrong: what Baxandall does here, and reports himself as doing, is to

\footnotetext{
${ }^{10} \mathrm{M}$. Baxandall, Shadows $\mathcal{E}$ Enlightenment (London: Yale University Press, 1995), pp.125-6.

${ }^{11}$ Op. cit. p.128.
} 


\section{Setting Things Before the Mind}

attend to what it is like for him to look out at the world around him, and attend now to the objects he recognises, now to the shadows by which they come to be visually defined for him.

When we follow the passage and see some surface now as textured and now as covered in skein of shadows, we learn something not only about the object we are attending to but also how we learn things visually about that object. The relation between the shadows and the texture seem to be ones which are forged within one's experience. It is this type of phenomenological fact which Baxandall focuses on. For this reason, if we are to find anything which deserves the epithet of description of what it is like for one to see, then Baxandall's account deserves such a title. It is, of course, a fragmentary such account, offering only a limited such description, partial in what it highlights and what it omits, and undoubtedly in much of its description highly theory-laden. None of that, I suggest, can take away from the clear sense a reader has, that what Baxandall does in the passage, and can be taken as intending to do, is describe his visual experience of the world, and not merely a description of the objects of perception. But if it is a description of his experience it also has to be a description of the objects he perceives, or takes himself to perceive. For what else could this feature be, if not an aspect of how the wall appears to one to be when one focuses on it now one way, now another?

What does this tell us about how we know what our experiences are like, and what we thereby know? First, the passage articulates much of what the experience is like, while at the same time leaving much unsaid, and perhaps unsayable. So it would be a mistake to suppose that the character of experience is entirely ineffable. Second, Baxandall indicates that he learns things about what it is like for him to view his study by paying careful attention in the way that he does to various features, and we the readers can certainly learn things not only about his inner life, but about our own, through reading the passage, and by following similar procedures. Even if there is a sense in which the character of our own experience is somehow obvious to us, that should not be taken to preclude the possibility that we can make discoveries about what experience is like. Third, and related to the above, learning about one's experience can involve active exploration, primarily of the experienced world 


\section{Setting Things Before the Mind}

around one, but in doing so of one's experience as well. Finally, correlative with the last, attending to what one's experience is like cannot be separated from exploring and attending to features of the world as perceived.

This suggests that the way in which we learn what our experiences are like is by attending first to the objects and features which are presented to us in perception. But there is an obvious problem with this suggestion: we can have perceptual experiences even when we are not perceiving anything in the physical world at all. One might have induced a perfect visual hallucination of a red tomato, rather than simply having the pleasure of seeing one all by itself. Furthermore, one might know full well that that is the position one is in. In such a case, one would not be in a position to scan the elements of the physical scene before one, nor would one take oneself to be in that position. Even in cases of hallucination, there is a way that one's experience is for one, and one can come to know what one's experience is like, yet there are no objects of perception for one to attend to.

Nevertheless, the basic model can still be applied even to this kind of case. For, in as much as an hallucination may be indistinguishable for one from a genuine perception, it will still seem to one as if there is an array of objects there for one to scan and explore. This will not necessarily be banished simply by the knowledge that one is suffering an hallucination, any more than the knowledge one is staring at a Müller-Lyer illusion is liable to make one see the lines as entirely equal in length. So in such a situation, one can still be interested in aspects of one's experience, and proceed to explore it by attending to the putative objects of awareness.

Note that the way we attend to our experiences when we reflect on them involves two distinct ways of attending. One can attend to something simply in thinking about it, as when I attend to the average rainfall in August in thinking that it is less than $1 / 2$ inch. When one reflects on one's own state of mind, one attends to it much as one attends to any object of thought. In addition, we can attend to objects that we perceive in ways that we are not related merely by thinking about them. As you read along this line, you may note that there are words ahead of the one your eye rests on at the moment, and that there are lines above, and below this one. Your eyes and your attention shift in 


\section{Setting Things Before the Mind}

turn from one word to the next. Now, as a whim, you might be inclined simply to turn your head away from the page to see what is going on in the world behind you. In that case, you shift your attention to a feature of your environment of which you are not currently aware. But, if you do not turn your head, but simply keep reading along the line, it may seem to you as if your attention is guided from the words that you now focus on, to the next set of words, by shifting among the features of which you are already aware. To the extent that you shift your attention, as a matter of voluntary control, rather than having your attention shifted, as when some distraction occurs at the periphery of vision, you seem to have the choice of moving your attention among the range of things of which you are already aware. So in perception, focal attention seems to range over objects which are already objects of awareness, and a motive for directing your attention to something, is to find out more.

Now in the case of reflecting on one's own experience, one attends to one's state of mind through directing one's attention over the actual or putative objects of awareness. Whether one is perceiving or merely hallucinating, there is an apparent array of objects for one to direct one's attention across. How things are as presented to one is surely one aspect of one's current state of mind: indeed, in a case of hallucination, directing one's attention to what is present will tell one nothing about what is present in one's environment in a case of hallucination. So, for this reason at least, exploiting perceptual attention is a way of coming to know about and attending to one's own experience. When one does so, one can't conceive of what one directs one's attention at as merely a property of one's experience, the way one is affected. For in directing one's attention across a visual scene, one may chose to direct one's attention to the feature on the left, rather than the one to the right. What one selects among are the putative objects presented at various apparent locations. But we do not think of our own experiences or their properties as spatially arrayed in this way. So the only sense that we can make of what one intends to do in attending to one's experience is that one does so through attending to things not taken to be merely properties of the experience.

As the Baxandall passage indicates, just such perceptual attention is exploited in coming to know about one's visual 


\section{Setting Things Before the Mind}

experience. So one cannot in so attending take what one attends to simply to be a way of being modified, as the adverbialist conception of experience claims. In as much as one exploits selective attention in learning about experience, such attention must range over the actual or putative objects of perception, and so attention to experience is not entirely distinct from attending to the objects of sense. To this extent at least, we should side with Price and the sense-datum theorists and not their adverbialist opponents. Of course, to attend to one's own state of mind is not the same thing as attending to some aspect of the world one is interested in, but given that one's state of mind has a certain subject-matter, one can attend to the state of mind, only by attending to that subject-matter. In the case of sensory experience, that requires that one direct one's attention at what is presented to one.

This point is revealed most clearly in the case of visual experience and other experiences, where its subject-matter is presented as spatially-arrayed. For we clearly do not take entities arrayed spatially to be merely the properties of mind. But it also holds more generally. We have here two contrasting conceptions of experience. On the adverbialist conception, we are to think of experience as simply being a state of the subject, a way of being modified. We are not to think of this event as intrinsically involving the presentation of anything to the subject, for that would be to import an 'act-object' conception of experience. Instead, experience is to be a modification in the way that being thirteen stone is a way of being modified. What marks the former out from the latter is just that this way of being is a way of being conscious. The alternative conception of experience places much more weight on the subject of experience, and the subject's viewpoint. On that conception, to have an experience is to have a viewpoint on something: experiences intrinsically possess some subject-matter which is presented to that viewpoint. To understand such experience and what it is like, one has to understand the viewpoint on that subject-matter, and hence also to attend to the subject-matter as presented to the viewpoint. ${ }^{12}$

\footnotetext{
${ }^{12}$ One can see Nagel's famous discussion of consciousness and physicalism, T. Nagel, 'What is it like to be a bat?', Mortal Questions, (Cambridge: Cambridge University Press, 1979), as principally
} 


\section{Setting Things Before the Mind}

So, if we could really just think of our experiences as ways of being affected, where the awareness of a subject-matter was not intrinsic to being in such a state, then we would have no reason to reject an adverbialist conception of such states of mind. However, when we think about sensory states such as visual experience, and more generally experiences of audition, smell, taste, even most bodily sensation, we cannot separate our knowledge of what it is like to be in that state from knowledge of the subject-matter presented to one in being in such a state of mind. But that suggests for all such experience that our awareness of what the experience is like is inextricably bound up with knowledge of what is presented to one in having such experience. To know what such experience is like is in part to know how things are presented to one as being.

Indeed, I would suggest, all of this can seem so obvious, once one thinks about it, that it should raise a problem of interpretation: how could anyone have plausibly put forward the adverbialist conception of experience as a serious option, given what we know of our experience? There are, I suggest, two aspects to the explanation of this: on the one hand, adverbialists were driven by a desire to reject the metaphysical commitments of sense-datum theories of perception; if taking seriously what we introspect of our experience would commit one to the existence of non-physical objects, then they were prepared to reject the apparently obvious. More insidious than this, though, the equivocation inherent in talk of 'qualia' which simply collapses the distinction between properties of being appeared to and properties apparent to one, simply obscures the inadequacy of the account.

employing the second conception of experience-it is the role of a subject's point of view within experience which explains why one must adopt a subject's point of view to understand what his experience is like, cf. pp. 166, 172, 173-4. In contrast, much of the discussion of the so-called 'Knowledge Argument' against physicalism tends to focus on the adverbialist conception of experience, where the focus on a subject's own perspective comes in only at the level of thinking about one's experience, and not in having the experience itself. 


\section{Setting Things Before the Mind}

3. We are now in a position to return to our initial task of laying out a common framework for the debate about the nature of experience and perceptual appearances. To know what one's experience is like is to know what properties, aspects or features are presented to one in having the experience. There seems to be no way to pick out the what it is like properties of the experiences without also picking out corresponding properties which objects may appear to have. It is no surprise, then, to find that the term 'qualia' is happy to migrate between the two. Our first step should then be to replace such ambiguous terminology with an explicitly defined terminology which allows of no such slippage.

We need to keep track of two distinct things and pose the question how they are to be related. On the one hand, we are concerned with states of mind, experiences, and how they can be the same or different from each other, in particular how they can be the same or different for the subject of such states: how it is for a perceiver when they are in one of these states rather than another. When talking about this aspect of perceptual situations, we might talk of the phenomenal character, or phenomenal properties of the experience. We shall use these terms strictly to apply only to experiences and their properties and not to the objects of experience and the properties they appear to possess. When we need to talk of the latter, as the above discussion indicates we need to in understanding the phenomenal properties of experience, we shall instead talk about the presented elements or presented aspects of an experience.

With these terms in hand we can then state the conclusions of the last section as the keystone for our framework to the debate: reflection on sensory experience should lead one to accept that there are at least some phenomenal properties of experience which have corresponding presented elements, and our understanding of the phenomenal properties is dependent on our understanding of their presented elements. On this view, difference in presented elements between two experiences will be sufficient for difference in their phenomenal properties. Note, incidentally, that Price commits himself to something much stronger in insisting on the diaphanous nature of experience: namely that sameness and difference of phenomenal properties just are sameness and difference in presented

elements. It is doubtful that this claim is true: why cannot the 


\section{Setting Things Before the Mind}

ways in which things are presented in experience make a difference to what the experience is like, in addition to what is presented?

We should at this point address the principal worry which motivates an adverbialist conception of experience: when we introduce talk of the presented elements of experience, and make differences between phenomenal properties of experience turn on them, are we not simply re-introducing sense-data into our account of experience? In seeing why not, we shall see how we are in a position to gain an overview of the whole debate. If we are to do justice to a subject's own point of view in having such experience, we need to fix on such presented elements; otherwise our account of experience will not be an account of what it is like for the subject of such experience to be so. From the subject's point of view, in both cases of perception and in cases of illusion and hallucination it certainly is as if there is something presented to her. So we can't do justice to that perspective without mentioning such a presented element in saying what the phenomenal character of her experience is. If we fail to mention such things then, as we saw, we end up with a view of experience on which it is not intrinsically a way of being aware of things.

But in doing this we need not take ourselves necessarily to be committed to the actual existence of these elements. For one might take a relaxed view of what the mention of a presented element in expressing the subject's point of view in having experience should commit one to. After all, we might think, in order to fix on young James's state of mind we have to mention Santa Claus, saying that James has asked his aunt for a Buzz Lightyear doll, but Santa Claus for a playhouse. At the very same time, we might simply add that James is more likely to be satisfied by his Aunt than Santa Claus, since at least the former but not the latter exists.

So too we might think in occupying the point of view in having an experience, we must act as if the elements presented or given are there. If we are to attend to what our experience is like, we need to attend to the various aspects of the presented array, and to do so is to treat them as if they really do exist. But in taking a certain distance from someone's experience, even in a moment of disbelief our own, we may not suppose that there 


\section{Setting Things Before the Mind}

really is anything answerable to what is presented to that point of view.

The key here is to realise that the thesis endorsed concerning the relation between phenomenal properties and presented elements is principally a claim about how we are to understand what experience is like for a subject, from the subject's point of view. To fix on what we are attempting to explain, what it is for one to have experience, we need to take seriously the first person point of view both in and on experience. It is then a further move to explain the metaphysical commitments of such experience, and asking what it takes for there both to be points of view and for there to be things, presented elements, on which such points of view are points of view. We can understand the fundamental debate about the nature of experience as a debate about these metaphysical commitments and the relation between phenomenal properties and presented elements.

Consider first the kind of intentional approach to perception which Dretske clearly favours. One will think that it is clear that the kind of experiences we have are intrinsically states of awareness of mind-independent objects and properties. So, one will identify the presented elements of such experiences with things that can exist independently of whether one has such experience. ${ }^{13}$ At the same time, in insisting on the representational nature of experience, Dretske allows for the possibility that such experiences may be illusory or hallucinatory. On this approach, one's experience may have the relevant phenomenal property without its corresponding presented element actually being there. We have here a two-way independence of presented elements and phenomenal properties.

On the other hand, we can interpret those philosophers who insist that there is a subjective aspect to perceptual experience as claiming that there are presented aspects of experience which could not exist independent of one's awareness of them, but which at the same time are guaranteed to be instantiated just in case one does have an experience with the appropriate phenomenal properties. Here we have the

\footnotetext{
${ }^{13}$ And in doing so, the theorist may claim to show how physical objects can be the direct objects of perception.
} 


\section{Setting Things Before the Mind}

mutual dependence of presented elements and phenomenal properties.

We can see these different views, then, as disputing two questions. On the one hand, they are concerned with what can be present to the mind: can the presented elements in experience exist independently of our awareness of them? On the other hand, they are concerned with the manner or mode in which objects are presented to one in having experience: can the presented elements of experience be so presented as not to require their actual existence for one's experience to be so. Indeed, we can think of these two questions as defining for us a complete set of options for the kinds of phenomenal property in question, depending on the mutual dependence of presented elements on phenomenal properties:

\begin{tabular}{|c|c|c|c|}
\hline \multirow[b]{2}{*}{ Is it possible to have: } & \multicolumn{3}{|c|}{$\begin{array}{l}\text { Is it possible to have: } \\
\text { Phenomenal Property \& } \\
\text { Not Presented Aspect? }\end{array}$} \\
\hline & & Yes & No \\
\hline Presented Aspect \& & Yes & Intentional & Naïve \\
\hline Not Phenomenal & No & Dependent & Subjective \\
\hline
\end{tabular}

Note that this generates four possible kinds of phenomenal property. For, one might agree with a defender of the intentional theory of perception that the presented elements of experience include the very mind-independent objects in the world around us which we take ourselves to perceive, and in that case that such presented elements can exist without one having the relevant experience. On the other hand, one might suppose, consonant with a sense-datum theory, that such experience really can only occur if its object really does exist, and hence that one can have an instance of the relevant phenomenal property only if its presented element exists. This possibility is marked in the matrix by the top right hand box: naïve phenomenal properties, as might call them. ${ }^{14}$ Likewise,

\footnotetext{
${ }^{14}$ Of course, one might think that the existence of illusions and hallucinations are enough to show that there cannot actually be any experiences with such phenomenal properties. Whether such
} 


\section{Setting Things Before the Mind}

one might think that while the subject-matter of experience could not exist independent of one's experience, and so its presented elements could not be instantiated without corresponding phenomenal properties, nevertheless the experience itself would not be sufficient to guarantee the existence of that subject-matter. This possibility is reflected in the bottom left box, labelled dependent phenomenal properties.

The debate about experience has tended to focus simply on the intentionality and subjectivity of experience, and hence on only two of these four properties, intentional phenomenal properties and subjective phenomenal properties in the terms of our matrix. ${ }^{15}$ Furthermore, those who insist on the intentionality or representational nature of experience have tended to emphasise its world-directedness: that the presented elements of our experiences are trees, tables and chairs which are there whether we experience them or not. But that aspect of experience is not sufficient to show that experience has intentional phenomenal properties rather than naive ones. Likewise, arguments for the existence of subjective phenomenal properties which attempt to show that there is more to what experience is like than how the external world is presented to be, cannot show by that that there are subjective phenomenal properties rather than that there are either subjective or dependent ones. One moral to draw from this discussion is that the debate in the literature has been drawn in terms which are too narrow. ${ }^{16}$ This gives us yet further evidence that the

arguments from illusion really establish that conclusion turns in part on how one assesses so-called disjunctive theories of perception as presented in P. F. Snowdon, 'Perception, Vision and Causation', Proceedings of the Aristotelian Society, (1980-81),, J. McDowell, 'Criteria, Defeasibility \& Knowledge', Proceedings of the British Academy, (1982), H. Putnam, 'The Dewey Lectures', fournal of Philosophy XCI, (1994).

${ }^{15}$ Cf. C. Peacocke, Sense E Content(Oxford: Clarendon Press, 1983), Ch.1, particularly the definition of sensational properties on p.5; G. Harman, 'The Intrinsic Quality of Experience', Philosophical Perspectives 4, J. Tomberlin (ed.) : Ridgeview Publishing Co, 1990); S. Shoemaker, 'Self-Knowledge and "Inner Sense"', Philosophy E Phenomenological Research 64, (1994),249-314.

${ }^{16}$ Note that the possession of any one phenomenal property does not exclude the possibility of having any of the others: so this generates fifteen possible accounts of perception. The discussion in the 


\section{Setting Things Before the Mind}

supposed obviousness of the terms of debate about subjective experience and qualia is nothing of the sort. We cannot hope to make proper progress on the debates about consciousness and the metaphysics of the mind until we have a better understanding of the issues surrounding perceptual experience and appearances.

The problem with which we started was that of finding some common ground between parties disputing what is supposedly just obvious to us. When that debate is framed simply in terms of the existence of qualia, or purely subjective qualities of experience, the problem is liable to seem intractable. But, I argued, such difficulties arise from the confusion inherent in the debate about qualia, with its almost unavoidable equivocation in the term. This we traced back to the adverbialist response to sense-data. The idea of experience merely as a mode of being affected by the world arises from the desire to avoid the metaphysical extravagances of sense-data, but it achieves metaphysical austerity only at the cost of leaving out of its conception of experience what seems to be essential to any account of what experience is like, that experience has a subject matter. Once we reject this misconception, we are then better placed to find the common ground between different views: they all do wish to hold onto a common conception that what experience is like is a matter of what is present to the mind. The differences between sense-datum theories of experience and intentional accounts of perception are disagreements about what can be set before the mind, and how it can be so set. These matters take us well beyond that which is simply obvious to one from reflection on one's own visual or

literature tends to focus solely on two or three of these: those which appeal purely to intentional phenomenal properties, cf. G. Harman, 'The Intrinsic Quality of Experience', Philosophical Perspectives 4, J. Tomberlin (ed.) : Ridgeview Publishing Co, 1990), and those who think that there must be a mixture of phenomenal and subjective properties, cf. C. Peacocke, Sense E Content(Oxford: Clarendon Press, 1983), Chs. $1 \& 2$; there are a few defenders of purely subjective accounts of experience, for example, F. Jackson, Perception: A Representative Theory(Cambridge: Cambridge University Press, 1977). 


\title{
Setting Things Before the Mind
}

auditory experiences. The question that remains is how we are to settle these disputes. ${ }^{17}$

\author{
MGF Martin \\ Dept of Philosophy, \\ University College London \\ LONDON WC1E 6BT.
}

\footnotetext{
${ }^{17}$ Talks from which this paper was drawn were given at a conference in Miskolc Tapolca, University College Dublin and the Institut für Philosophie Universität München, I am grateful to those audiences and the one at the Royal Institute for their questions and comments. I would also like to thank Paul Boghossian, Tim Crane, Naomi Eilan, Norbert Niclauss, Scott Sturgeon for detailed comments and discussion of these matters. Work for this paper was carried out while on research leave sponsored by the British Academy.
} 